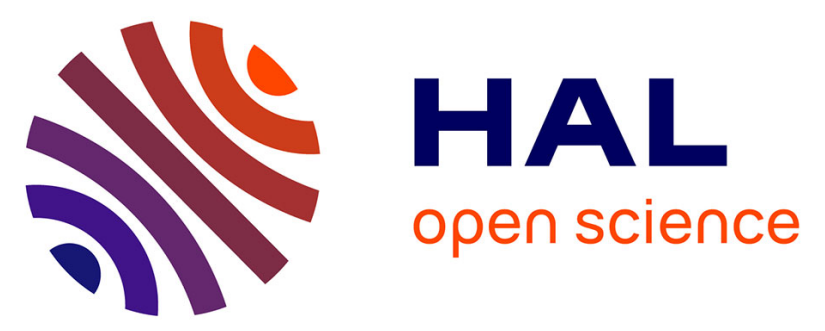

\title{
Contribution of stratospheric warmings to temperature trends in the middle atmosphere from the lidar series obtained at Haute-Provence Observatory $\left(44^{\circ} \mathrm{N}\right)$
}

\author{
Guillaume Angot, Philippe Keckhut, Alain Hauchecorne, Chantal Claud
}

\section{- To cite this version:}

Guillaume Angot, Philippe Keckhut, Alain Hauchecorne, Chantal Claud. Contribution of stratospheric warmings to temperature trends in the middle atmosphere from the lidar series obtained at Haute-Provence Observatory $\left(44^{\circ} \mathrm{N}\right)$. Journal of Geophysical Research: Atmospheres, 2012, 117 (D21), pp.D21102. 10.1029/2012JD017631 . hal-00749188

\author{
HAL Id: hal-00749188 \\ https://hal.science/hal-00749188
}

Submitted on 1 May 2016

HAL is a multi-disciplinary open access archive for the deposit and dissemination of scientific research documents, whether they are published or not. The documents may come from teaching and research institutions in France or abroad, or from public or private research centers.
L'archive ouverte pluridisciplinaire HAL, est destinée au dépôt et à la diffusion de documents scientifiques de niveau recherche, publiés ou non, émanant des établissements d'enseignement et de recherche français ou étrangers, des laboratoires publics ou privés. 


\title{
Contribution of stratospheric warmings to temperature trends in the middle atmosphere from the lidar series obtained at Haute-Provence Observatory $\left(44^{\circ} \mathrm{N}\right)$
}

\author{
Guillaume Angot, ${ }^{1}$ Philippe Keckhut, ${ }^{1}$ Alain Hauchecorne, ${ }^{1}$ and Chantal Claud ${ }^{2}$ \\ Received 15 February 2012; revised 19 September 2012; accepted 21 September 2012; published 1 November 2012.
}

[1] This study describes a method to calculate long-term temperature trends, as an alternative to the ones based on monthly mean temperatures, which are highly impacted by the high winter variability partially due to wave-mean flow interactions like Sudden Stratospheric Warmings (SSW). This method avoids the strong influence of SSWs and provides "background" temperature trend estimates which are in better agreement with expected direct radiative effects. The data set used results from lidar measurements - performed above southern France continuously since late 1978 - combined with radiosonde profiles. With this new methodology, the long-term trends during winter at $40 \mathrm{~km}$ shows a larger cooling per decade $(-2 \pm 0.4 \mathrm{~K})$ than when the mean temperature is used $(-0.4 \pm 0.4 \mathrm{~K})$. The background temperature trend is closer to the summer trend estimates which are similar whatever the temperature proxy used, due to the absence of SSWs $(-2.9 \pm 0.3 \mathrm{~K}$ per decade with the mean-based method and $-3.4 \pm 0.3 \mathrm{~K}$ per decade with the background-based calculation). Based on this background temperature, composite evolutions of winter anomalies for both vortex-displacement and vortex-splitting major SSWs have been displayed: in both cases the largest warming occurs at the time of the SSW in the upper stratosphere, with mean amplitudes of more than $10 \mathrm{~K}$. A warm signal in the upper mesosphere could suggest a potential precursory role of gravity waves. Displacement-type events present an 18-day periodicity, which is a clear sign of the wave number one Rossby wave. Colder tropospheric temperatures are noticed before and during the SSW, and warmer ones after the event, with a stronger signal for split-type events.

Citation: Angot, G., P. Keckhut, A. Hauchecorne, and C. Claud (2012), Contribution of stratospheric warmings to temperature trends in the middle atmosphere from the lidar series obtained at Haute-Provence Observatory (44 N), J. Geophys. Res., 117, D21102, doi:10.1029/2012JD017631.

\section{Introduction}

[2] The middle atmosphere is expected to continuously cool due to the increase of greenhouse gases [Rind et al., 1998]. Without any strong political regulation process, the cooling rate should persist except if the natural sinks of carbon dioxide (ocean and biosphere) evolve. Stratospheric ozone decrease has led to an additional cooling in the upper stratosphere [Hare et al., 2004; Cagnazzo et al., 2006]. The induced cooling rate is expected to be roughly of the same

\footnotetext{
${ }^{1}$ Laboratoire Atmosphères, Milieux, Observations Spatiales, UMR 8190 Institut Pierre-Simon Laplace, Université Versailles-Saint Quentin, Guyancourt, France.

${ }^{2}$ Laboratoire de Météorologie Dynamique/IPSL, CNRS, UMR 8539, École Polytechnique, Palaiseau, France.

Corresponding author: G. Angot, Laboratoire Atmosphères, Milieux, Observations Spatiales, UMR8190, Institut Pierre-Simon Laplace, Université Versailles-Saint Quentin, Quartier des Garennes, 11 Boulevard D'Alembert, FR-78280 Guyancourt, France. (guillaume.angot@latmos.ipsl.fr)

(C)2012. American Geophysical Union. All Rights Reserved. 0148-0227/12/2012JD017631
}

order of magnitude than the cooling due to greenhouse gases (respectively $-1.3 \mathrm{~K}$ per decade and $-1.2 \mathrm{~K}$ per decade). However, the temperature change due to global ozone depletion is probably close to its maximum due to the reduction of ozone depleting substances.

[3] Long-term temperature trends based on monthly mean temperatures have been estimated with different data sets retrieved from ground-based instruments (radiosondes, rockets, lidars), meteorological satellites and analyses, showing coolings differing in magnitude. Besides, these estimations suffer from instrumental drifts, discontinuities and spatiotemporal sampling [Ramaswamy et al., 2001; Beig et al., 2003; Randel et al., 2009]. While long-term trends were focused on monthly mean temperatures' changes, temperature variability can be large, mainly in winter. Therefore the mean quantity appears to be a poor proxy when data length is short. As pointed out by Nishizawa and Yoden [2005], uncertainty on trend estimates is also increased by periodic external forcings with long periods, such as the 11-year solar cycle; intermittent external forcings with long intervals, such as major explosive volcanic eruptions; or sudden level shifts of data quality, such 
as changes in instruments. Multiregression analyses have been utilized to take into account the natural superimposed variability, however they still exhibit a lot of uncertainties [Weatherhead et al., 1998; Kerzenmacher et al., 2006] when variability is large and not normally distributed, and when proxies are nonlinearly related to investigated series. Spurious trend estimates can then be derived and enhanced due to different time sampling [Funatsu et al., 2008]. Regional variability further complicates the determination of trends, as shown by Funatsu et al. [2011]. Nishizawa and Yoden [2005] show that more detailed distribution analyses could improve trend estimates and are helpful to separate the different causes of variability. It is particularly applicable when threshold mechanisms are concerned like polar clouds formation [David et al., 2009], or with the occurrence of extreme or rare events.

[4] Middle atmosphere temperature variability is also driven by dynamics. During winter, midlatitudes and highlatitudes are affected by sudden stratospheric warmings (SSWs) [Labitzke, 1972; O'Neill, 2003] due to wave-mean flow interactions that decelerate the fast eastward jet stream which characterizes the polar vortex. As a consequence, the vortex is distorted from its polar-centered position (forced by radiative processes) and very large increases in temperature $(10 \mathrm{~K}$ to $60 \mathrm{~K})$ can be observed over several weeks [von Zahn et al., 1998] when the vortex breaks down. An associated cooling is also noticed in the mesosphere [Cho et al., 2004; Keckhut et al., 2011]. The stratospheric jet reversal allows more eastward-propagating gravity waves into the mesosphere, which leads to a strong feedback in the mesosphere [Liu and Roble, 2002; Hoffmann et al., 2007]. While these effects are simulated with numerical models [Matsuno, 1971; Hauchecorne and Chanin, 1988], the exact conditions of their occurrence are not obvious and are still difficult to predict. Anomalies in the Arctic Oscillation seem to be induced by the stratosphere first [Thompson and Wallace, 1998], with a time lag of several weeks [Baldwin and Dunkerton, 2001]. Even if the exact processes are not precisely known, these studies suggest a role of the stratosphere on climate.

[5] SSWs happen when the eastward mean flSW of the polar stratosphere interacts with upward propagating planetary waves, consisting primarily of zonal wave numbers 1 and 2 [Matsuno, 1971; Andrews et al., 1987]. Atmospheric gravity waves may also play a role in the appearance of SSWs when they propagate into the stratosphere thanks to variations of the tropopause jet during instabilities in the upper troposphere [Flury et al., 2010]. SSWs are the largest stratospheric perturbations and explain the majority of the stratosphere's inter-annual variability; therefore their occurrence is an important issue for climate research. Their evolution was arbitrarily characterized according to their intensity, and partitioned as major or minor warming depending whether the zonal wind decrease at $60^{\circ} \mathrm{N}$ was sufficient to make the wind reverse [Labitzke, 1981]. Charlton and Polvani [2007] suggest a classification regarding the impact on vortex dynamics: vortex-displacement and vortex-splitting events. Even more recently, investigations continue [Matthewman et al., 2009] on the 3D evolution: they establish that both types of warming events exhibit repeatable behaviors and characteristics, and they show that useful composite evolutions can be built for comparisons with numerical model evaluations.
[6] Temperature lidar measurements performed above southern France since late 1978 have been used extensively to derive vertical profiles of temperature trends [Hauchecorne et al., 1991; Keckhut et al., 1995, 2011] based on standard regression analyses of monthly mean temperature. These observations performed in the frame of the NDACC (Network for the Detection of Atmospheric Composition Change) have been complemented with additional stations at different locations [Li et al., 2011] and satellite instrument drift evaluations [Keckhut et al., 2011]. Continuous lidar measurements have also been used to report temperature evolutions during SSWs in the stratosphere and mesosphere [Hauchecorne and Chanin, 1983]. However, to our knowledge, statistical analyses of winter evolution according to stratospheric warmings have never been performed on long data sets, and the contribution of such events on trend estimates has never been assessed.

[7] This study aims to estimate long-term temperature evolutions with a different method than the ones based on monthly mean temperatures, so as to provide trend estimates in better agreement with direct radiative effects. With more representative estimates of the background temperature and a multidecadal lidar data set, anomalies associated with stratospheric warmings are better quantified and composite evolutions of stratospheric warmings can be derived up to the mesopause, complementing previous works on the characterization of the time evolution of such phenomena.

[8] The present paper is structured as follows. Section 2 gives details about the lidar data set. In section 3, we explain the concept of "background temperature," in contrast to mean temperature, and we describe how to retrieve it. In section 4, trends based on this new estimate are derived and compared with similar estimates on mean temperatures. Section 5 provides composite evolutions of the temperature during SSWs. Finally, a discussion of the results and conclusions are presented in section 6 .

\section{Data Description}

[9] The temperature time series used in this study results from lidar measurements performed continuously at HauteProvence Observatory above southern France (HPO: $44^{\circ} \mathrm{N}$, $6^{\circ} \mathrm{E}$ ), from October 1978 to December 2009. This constitutes the longest lidar temperature series. The measurements are performed in the frame of the NDACC network since 1991, archived by the ETHER French Atmospheric Chemistry Group (http://www.ether.ipsl.fr) at the NDACC database hosted by NOAA, and available publicly at http:// www.ndacc.org. Temperature profiles are deduced using Rayleigh scattering [Hauchecorne and Chanin, 1980]. Initially, the vertical resolution was $300 \mathrm{~m}$, and it has been improved to $75 \mathrm{~m}$ since 1994 . In order to perform climatologic analyses, data are smoothed similarly and vertically with a $3 \mathrm{~km}$ running Hanning window. Time integrations are typically between 2 and $3 \mathrm{~h}$ but could vary from $1 \mathrm{~h}$ to $12 \mathrm{~h}$ and profiles reach maximum altitudes between $75 \mathrm{~km}$ and $90 \mathrm{~km}$. The statistical accuracy is smaller than $1 \mathrm{~K}$ below $70 \mathrm{~km}$, and then it increases with altitude. Systematic bias can occur around $30 \mathrm{~km}$ and above $70 \mathrm{~km}$ [Keckhut et al., 1993], however cross-validation performed within NDACC with a mobile system [Singh et al., 1996], or with satellites as geographical transfer [Wild et al., 1995], as well as algorithm inter-comparisons [Leblanc et al., 1998] do not reveal strong 
Table 1. Category of the Winters for the Period 1985-2009

\begin{tabular}{cl}
\hline Winter & \multicolumn{1}{c}{ Category } \\
\hline $1985-1986$ & Without major SSW \\
$1986-1987$ & With major SSW \\
$1987-1988$ & With major SSW \\
$1988-1989$ & Without major SSW \\
$1989-1990$ & Without major SSW \\
$1990-1991$ & Without major SSW \\
$1991-1992$ & Without major SSW \\
$1992-1993$ & Without major SSW \\
$1993-1994$ & Winter excluded \\
$1994-1995$ & Without major SSW \\
$1995-1996$ & Without major SSW \\
$1996-1997$ & Without major SSW \\
$1997-1998$ & Without major SSW \\
$1998-1999$ & With major SSW \\
$1999-2000$ & With major SSW \\
$2000-2001$ & With major SSW \\
$2001-2002$ & Winter excluded \\
$2002-2003$ & With major SSW \\
$2003-2004$ & Winter excluded \\
$2004-2005$ & Without major SSW \\
$2005-2006$ & With major SSW \\
$2006-2007$ & Winter excluded \\
$2007-2008$ & With major SSW \\
$2008-2009$ & With major SSW \\
\hline
\end{tabular}

bias [Keckhut et al., 2004] except during major volcanic eruptions when aerosols reach in some cases altitudes above $30 \mathrm{~km}$ [Keckhut et al., 2005]. These data are removed and temperature above $90 \mathrm{~km}$ is not considered.

[10] Temperature profiles are extended downward using radiosondes performed at Nîmes (located $60 \mathrm{~km}$ east of HPO). Radiosondes are launched by the French weather service, Météo-France, twice a day: at noon and midnight. The successive radiosonde models used were: the MESURAL sonde (from 1978 to 1981), then VAISALA models (RS80 until summer 2001, RS90 until summer 2005 and RS92), and finally they were replaced in mid-2007 by the MODEM M2K2DC. Concerning the period 2001-2009, the maximum altitude reached by the radiosondes averages $24.5 \mathrm{~km}$, and the mean number of missing data is 11.5 days per year. The inaccuracy of radiosondes measurements comes from both errors in determining the altitude from the pressure and in the temperature measurement itself [Keckhut et al., 1993]. Both errors account for $1 \mathrm{~K}$ to $3 \mathrm{~K}$ maximum at $30 \mathrm{~km}$. However, the measurement accuracy has increased to $0.2 \mathrm{~K}$ since 2005 when a GPS system was implemented to determine the altitude of the radiosonde balloon. Overall, comparisons between lidar and such radiosondes measurements with the altitude monitored show close concordance (around $30 \mathrm{~km}$ ) with a difference of never more than $1 \mathrm{~K}$. Jeannet et al. [2008] listed different radiosonde comparisons from simultaneous measurements. The nighttime temperature bias at $10 \mathrm{hPa}$ improves from a little bit more than $4 \mathrm{~K}$ in 1984 to less than $2 \mathrm{~K}$ since 2001, and the random errors for the same measurements decrease from $2 \mathrm{~K}$ in 1984 to less than $0.5 \mathrm{~K}$ since 1993 . Other reports (Vaisala white paper, Vaisala radiosonde RS92 performance in the WMO intercomparison of high quality radiosonde systems, 2011) confirm that recent instruments enable nighttime measurements with accuracies as low as 0.3
$\mathrm{K}$ below $16 \mathrm{~km}$ and $0.6 \mathrm{~K}$ above. Radiosonde temperatures at 00 UTC are merged with lidar data using a linear interpolation.

[11] There are 3678 lidar profiles available (with a vertical resolution of $3 \mathrm{~km}$ ) covering more than 31 years from late 1978 to 2009, which corresponds to almost one day out of three. Monthly number of days of measurements is illustrated and studied by Keckhut et al. [2011]. Mean lag of missing data is 2.1 days (it is reduced to 1.7 days if we exclude the 19 periods when the measurements were stopped for more than 40 days due to instrumental failures or standby of operations), with a pseudo standard deviation of 7.1 days (3.5 days when not considering the 19 gaps mentioned above). Overall data quality is better in recent years than in earlier ones. Indeed, measurements have been performed more often and more regularly: 8 of the 19 biggest gaps happened before 1981. Moreover, thanks to laser power increase, the measurements were progressively extended to the $90 \mathrm{~km}$ level: the first profiles, obtained in late October 1978, reached $61 \mathrm{~km}$, and $63 \mathrm{~km}$ within a fortnight, while level $67 \mathrm{~km}$ was met the last day of the year. After two years, the measurements could go up to $76 \mathrm{~km}$ (late January 1981). Six month later, level $84 \mathrm{~km}$ was reached, then one more year was needed for the measurements to go up to $89 \mathrm{~km}$ (in May 1982), and finally level $90 \mathrm{~km}$ was first met in late December 1983. Besides, the measurement error has been reduced throughout the years thanks to increasing instrument quality and better understanding of the error sources [Keckhut et al., 1993].

[12] A linear extrapolation has been carried out so as to get daily values from the measurements. The biggest gaps are avoided in the study either because they happen in the summer or, when necessary, with the exclusion of specific winters from the calculations (see Table 1).

[13] Though Haute-Provence Observatory is a midlatitude station, it allows the study of polar vortex disturbances. Indeed, the polar night jet can be encountered as low as $40^{\circ} \mathrm{N}$. Moreover, the polar vortex does not stay strictly vertical, but rather can be highly distorted, especially during important dynamical events such as displacement-type SSWs. Then, the lower part of the vortex (below $30 \mathrm{~km}$ ) is usually shifted toward Europe, while the higher part is located in a more western region, as can be seen in the maps provided by MIMOSA (http://ether.ipsl.jussieu.fr/etherTypo/ index.php? $\mathrm{id}=1283 \& \mathrm{~L}=1)$. This is corroborated by Godin et al. [2002] who study ozone concentrations over HauteProvence Observatory and show vortex excursions happen above the station.

\section{The Background Temperature Annual Cycle}

\subsection{Temperature Climatology}

[14] The annual evolution of the temperature at $40 \mathrm{~km}$ (calculated with a "standard" moving average; see Figure 1) shows a strong annual cycle ranging from $243 \mathrm{~K}$ in November to $258 \mathrm{~K}$ in June, while at $65 \mathrm{~km}$ there is also a semiannual signature (the minimum value is in late December at $223 \mathrm{~K}$ and the maximum is reached in November at $239 \mathrm{~K}$ ). An anti-correlation between the two evolutions is visible during the winter period. The semiannual signature concerns the higher altitudes, and appears around $55 \mathrm{~km}$. These evolutions could be approximated by sinusoidal functions [She et al., 1995; Leblanc et al., 1998]. 


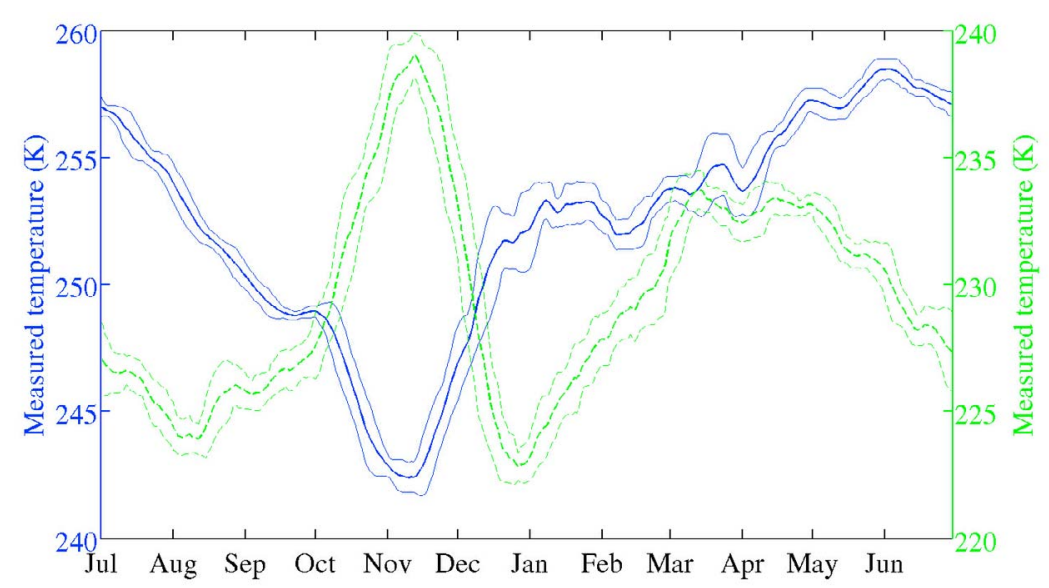

Figure 1. Moving average over 15 days of the mean annual temperature cycle calculated over the three decades covered by the measurements $(1979-2009)$. Level $40 \mathrm{~km}$ (blue solid line) and $65 \mathrm{~km}$ (green dashed line). Thin lines represent plus and minus one standard deviation (from average) plots.

However, in winter two factors perturb the evolution at $40 \mathrm{~km}$. First, the variability is greater than in summer (the mean standard deviation for winter is $1.0 \mathrm{~K}$, whereas it is $0.5 \mathrm{~K}$ for summer) as pointed out by Hauchecorne et al. [1991]; second, the temperature is warmer than the expected annual sine curve. These are clear signatures of strong dynamical events occurring in winter at midlatitudes and high-latitudes, such as SSWs.

[15] The distributions of temperature anomalies using all the data (around 30 years) sampled into fifteen-day periods (1st half of January, 2nd half of January, 1st half of February, etc.) show (Figure 2) simple-bell-shaped or double-bellshaped curves. Double-bell shapes are observed in winter periods, which are affected by reinforced dynamical perturbations. The second, warmer bell curve is related to the winter warmings noticed above. Therefore, in winter the mean temperature is not linked to a single physical phenomenon: the statistical distributions rather suggest that two populations of temperatures have to be distinguished. The first one corresponds to the background temperature associated with radiative processes and any other continuous dynamical contributions; the second one results from strong dynamical events like stratospheric warmings (the method used to both determine and identify the Gaussians is explained in Appendix A). Note that major SSWs (see Table 2 for a list of their dates) temperatures almost always fall within the latter Gaussian. This reinforces our hypothesis that the distribution analysis presented in this paper is a good method for extracting the background temperature distribution. In one case, the increase of temperature resulting from the SSW appears in the data four days after the event: this can be interpreted as the warming being not yet located above the station at the time of the event (especially since this is a displacement event).
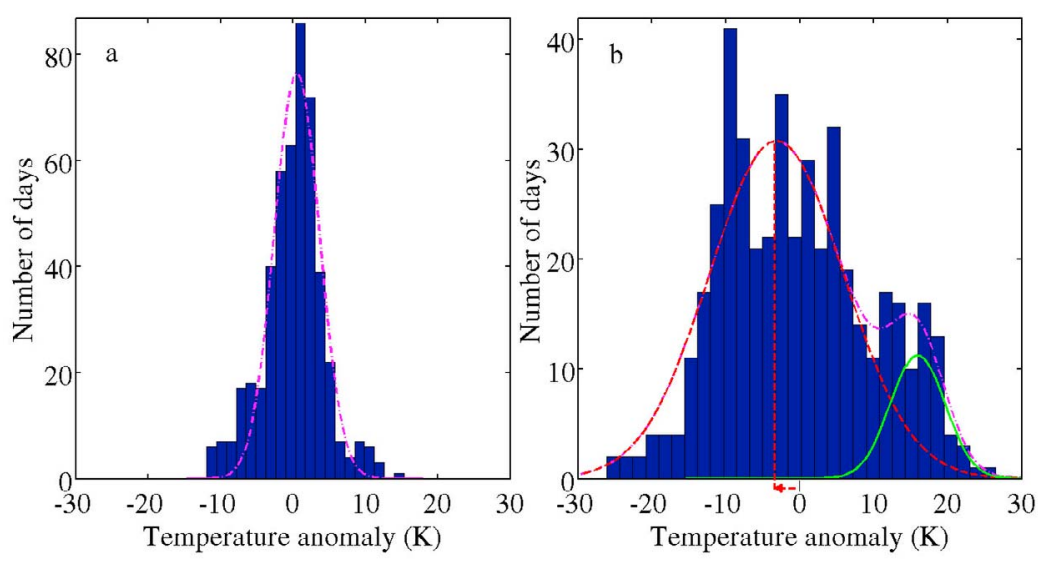

Figure 2. Temperature anomalies distributions at $40 \mathrm{~km}$ during (a) the second half of May and (b) the first half of February. Here, temperature anomalies are defined as the difference between the measurements and the "standard" annual temperature cycle seen in Figure 1. The data considered spans over 31 years, from 1979 to 2009 . Magenta dash-dotted lines show simple or double Gaussian fit of the distributions. In the latter case, red-dashed and green-solid Gaussian curves represent the individual components of the fit. The red arrow highlights the temperature anomaly (here $-3.2 \mathrm{~K}$ ) used in a calculation presented below (see Figure 3). 
Table 2. Dates and Types (D for Displacement and S for Split) of the Major SSWs Considered in This Study

\begin{tabular}{lc}
\hline \multicolumn{1}{c}{ Date } & Type \\
\hline 4 Dec 1981 & $\mathrm{D}$ \\
1 Jan 1985 & $\mathrm{~S}$ \\
23 Jan 1987 & $\mathrm{D}$ \\
7 Dec 1987 & $\mathrm{~S}$ \\
14 Mar 1988 & $\mathrm{S}$ \\
15 Dec 1998 & $\mathrm{D}$ \\
26 Feb 1999 & $\mathrm{S}$ \\
20 Mar 2000 & $\mathrm{D}$ \\
11 Feb 2001 & $\mathrm{S}$ \\
18 Jan 2003 & $\mathrm{S}$ \\
21 Jan 2006 & $\mathrm{D}$ \\
22 Feb 2008 & $\mathrm{D}$ \\
24 Jan 2009 & $\mathrm{S}$ \\
\hline
\end{tabular}

[16] These observations indicate that a method based on the most probable value should provide a better estimation of the temperature associated with direct radiative effect than methods relying upon mean temperatures.

[17] For summer periods or at lower altitudes, where the variability is smaller, the distribution is mono-modal and its shape looks more like a Gaussian curve (see Appendix A).

[18] Resulting from the analysis of the temperature anomalies described previously, a new method for investigating long-term changes is put forward. It is based on the following main hypothesis: the measured temperature is the sum of two components: (1) a temperature linked to events which represent a background state, and (2) a contribution related to events associated with large dynamical disturbances. From now on, this contribution is named "temperature anomaly," or just "anomaly."

$$
T_{\text {measured }}=T_{\text {background }}+T_{\text {anomaly }}
$$

The background temperature corresponds to the temperature resulting from the equilibrium state of the atmosphere, mainly driven by direct radiative forcings and the mean composition, with a standard background dynamical activity from gravity waves and planetary waves. Therefore, the background temperature depends on parameters such as sun activity [Keckhut et al., 2005; Dunkerton et al., 1998], greenhouse gases concentration [Rind et al., 1998], stratospheric ozone and aerosol loading for the lower stratosphere. In our study the background temperature annual cycle is the same for all years. The temperature anomaly is defined as the difference between the measured temperature and the background one. It is linked to reinforced dynamical activity, such as the breaking of planetary waves, leading to sudden stratospheric warmings. But the temperature anomaly also depends on greenhouse gases concentrations, as their increase has consequences on the middle atmosphere's dynamics, in particular on SSWs.

\subsection{Extraction of the Background Temperature}

[19] The methodology to retrieve the background temperature is based on the distributions of the temperature anomalies - described in the previous section (3.1) - for 24 fifteen-days intervals evenly distributed throughout the year. Reinforced dynamical activity occurs for the most part in winter, and tends to warm up the atmosphere [Andrews et al., 1987]. Therefore, the background temperature of the 15-days period studied corresponds to (the abscissa of) the peak of the background Gaussian curve (as identified using the methodology described in Appendix A). (Note that in order to calculate the actual background temperature, we add the mean temperature of the 15-day interval to the appropriate Gaussian peak.) This method leads to 24 values, which we fit by a sine curve (or the sum of two sine curves) to retrieve the background temperature.

[20] The effect of winter warmings on measured temperatures clearly appears when comparing the background temperature to the "standard" moving average annual cycle at level $40 \mathrm{~km}$ (Figure 3). When the sum of two sine curves (one annual and one semiannual) is used to fit the data, we notice that the semiannual component is no more negligible above $55 \mathrm{~km}$. The annual cycle amplitude is quite stable around $6 \mathrm{~K}$ from $30 \mathrm{~km}$ to $50 \mathrm{~km}$; then reaches a minimum of $1.5 \mathrm{~K}$ at $65 \mathrm{~km}$; and finally rises up to $15 \mathrm{~K}$ at $80 \mathrm{~km}$. These results are in good agreement with the ones provided

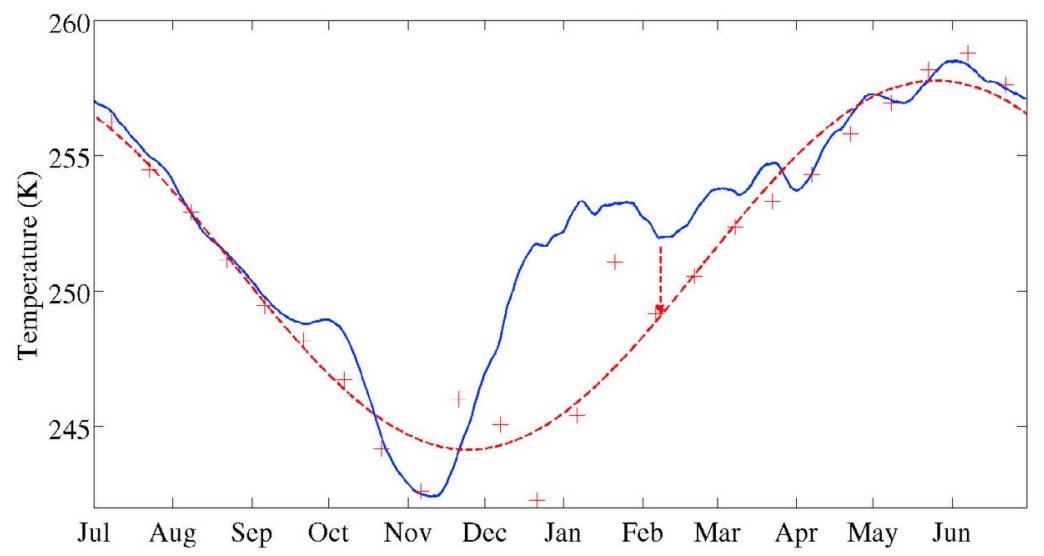

Figure 3. Background temperature (red dashed line) and "standard" annual cycle (blue solid line) based on mean temperatures at $40 \mathrm{~km}$. The red crosses represent the 24 values calculated to determine the background temperature. The red arrow indicates how the temperature anomaly calculated in Figure 2 is used to place the cross. 


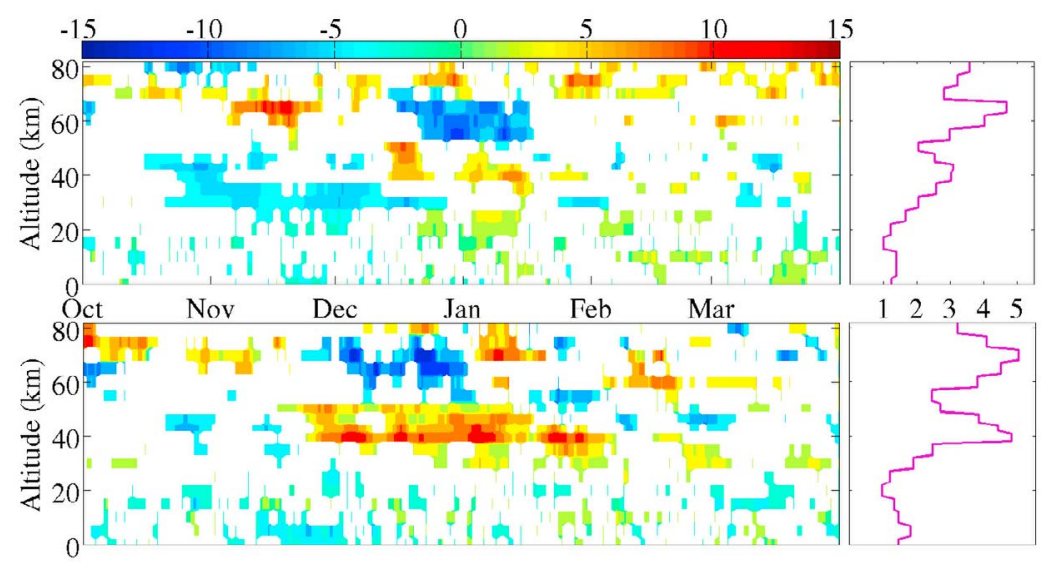

Figure 4. Mean temperature anomaly evolution (in K) from October 1st to April 1st for years (top) without and (bottom) with major SSW. Altitude spans from ground level to $82 \mathrm{~km}$. The magenta profiles show the mean temperature variability (for the same altitude range). Top and bottom plots share the same abscissas.

by She et al. [1995]. Moreover, the annual phase is in June at $30 \mathrm{~km}$ and $50 \mathrm{~km}$, in May at $40 \mathrm{~km}$, and in January above $65 \mathrm{~km}$. Concerning the semiannual amplitude, it reaches its maximum at $65 \mathrm{~km}$ and its minimum at $75 \mathrm{~km}$. As reported by Leblanc et al. [1998], the semiannual component is weaker than the annual component, except at the altitude of annual phase inversion $(65 \mathrm{~km})$.

[21] Therefore, the modelization proposed for the background temperature is a sinusoidal one below $55 \mathrm{~km}$ :

$$
T_{\text {background }}=T_{\text {mean }}+\Delta T_{\text {annual }} \cdot \sin \left(2 \pi j / 366+\varphi_{0}\right)
$$

where $\Delta T_{\text {annual }}$ is the temperature amplitude of the seasonal cycle, $\mathrm{j}$ represents the day of the year, and $\varphi_{0}$ is the initial phase. Above $55 \mathrm{~km}$, the background temperature is assumed to result from the sum of two sine curves with periods of one year and six months:

$$
\begin{aligned}
T_{\text {background }}= & T_{\text {mean }}+\Delta T_{\text {annual }} \cdot \sin \left(2 \pi j / 366+\varphi_{0, \text { annual }}\right) \\
& +\Delta T_{\text {semi-annual }} \cdot \sin \left(2 \pi j / 183+\varphi_{0, \text { semi-annual }}\right)
\end{aligned}
$$

\section{Trend Estimates}

\subsection{Winter Anomalies Evolution}

[22] To estimate the anomaly amplitudes during winters, the sinusoidal background temperature annual cycle from equations (2) and (3) has been subtracted. Then mean time evolution is calculated by averaging several winters according to the time of the warming, to identify the systematic features that can be associated with stratospheric warmings.

[23] The mean anomaly is calculated over the period extending from winter 1985-1986 to winter 2008-2009. The older data were not selected because of the quality and time sampling improving with time, as described in section 2 . Starting in 1986 allows to both avoid the first years of relatively poor quality data and keep enough winter periods to perform the calculation of the mean temperature and to feature a strong climatologic meaning.
[24] To be able to clearly identify effects associated with stratospheric warmings, winters were partitioned according to the occurrence of such events. Table 1 gives information about the category in which each winter of this period falls into, according to the presence of a major SSW (as described by Charlton and Polvani [2007]) and to the data quality, which a few times was too poor and led to the exclusion of the associated winter of the calculations. The study is limited to major events because they are the only ones that can really be characterized with a quantitative proxy from horizontal meteorological fields [Labitzke, 1981]. The 24 winters are distributed as follows: nine presented a major SSW, eleven did not, and four are excluded.

[25] The mean evolutions of temperature anomalies for winter periods (October to March) with and without major SSW exhibit similarities, but also some differences (Figure 4). The variability along the winter is also calculated at each altitude level. From this point forward, the variability profile of winters without major SSW is chosen as a reference to estimate the significance of temperature anomalies: any temperature anomaly above this threshold is taken into account whereas lower anomalies are considered as nonsignificant, and thus are not shown. As already stated, the anomalies are calculated thanks to a comparison to the sinusoidal background temperature annual cycle from equations (2) and (3), which is the reference in this study.

[26] Both time evolutions show the same general pattern with time and altitude. This is not fully surprising as SSWs occur each winter, and only a few of these events are big enough to be qualified as major. Therefore, the effects of pronounced minor warmings are visible in both panels of Figure 4. This general pattern is characterized by warm anomalies which appear at $70-80 \mathrm{~km}$ in the first half of October; at $40-50 \mathrm{~km}$, from early December to early February; and at $75-80 \mathrm{~km}$ in December and January. Regions of cold anomalies associated with the warm periods can be pointed out, in particular at level $60-70 \mathrm{~km}$ in December and early January. Another cold anomaly descends from the lower mesosphere $(55-65 \mathrm{~km})$ in early October to the level $25-35 \mathrm{~km}$ in December. At $55-60 \mathrm{~km}$ a region of small variability is noted. Overall, the evolution is 


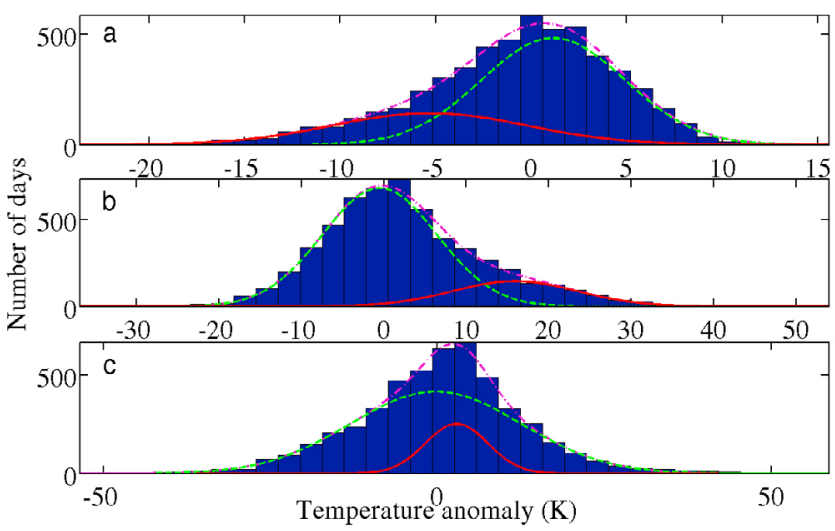

Figure 5. Winter temperature anomalies distributions at (a) $5 \mathrm{~km}$, (b) $40 \mathrm{~km}$ and (c) $70 \mathrm{~km}$. The data considered spans over 31 years, from 1979 to 2009. Magenta dash-dotted lines show the fit of the distributions. Green-dashed and red-solid Gaussian curves represent individual components of the fit.

characterized by a strong anti-correlation between levels $40 \mathrm{~km}$ and $65 \mathrm{~km}$, for both winter types. This has already been noticed in previous studies, and recently clearly established on this data set through an EOF analysis [Keckhut et al., 2011]. The main warming pointed out at $40 \mathrm{~km}$ from December to February corresponds to the period when stratospheric warmings happen the most frequently. The apparent propagation of the warming, experienced for both winter types, may probably be associated with a mean deceleration of the vortex starting in the upper mesosphere.

[27] The differences between the two plots lie mainly in the intensity of the temperature anomalies described above, but also in some anomalies present in one diagram and not in the other, as well as in anomalies slightly in advance or occurring higher in one plot compared to the other. Anomalies intensity is generally larger for winters with major SSW. In December the temperature anomalies reach $+10 \mathrm{~K}$ to $+15 \mathrm{~K}$ at $40-50 \mathrm{~km}$ and $-10 \mathrm{~K}$ to $-15 \mathrm{~K}$ at $60-70 \mathrm{~km}$ whereas the similar anomalies for winters without major $\mathrm{SSW}$ are $+3 \mathrm{~K}$ to $+8 \mathrm{~K}$ and $-6 \mathrm{~K}$ to $-11 \mathrm{~K}$. The main warm anomaly at $40 \mathrm{~km}$ also lasts longer for winters with major SSW, starting as early as late November and ending only in February. However, the warming at $65 \mathrm{~km}$ in November is more pronounced for winters without major SSW. Besides, the following cooling around the same altitude occurs 15 days later than for winters with major SSW. Concerning these winters, the troposphere levels reveal a cold anomaly (up to $-5 \mathrm{~K}$ ) extending from mid-November to mid-December followed by a warm anomaly; whereas there is no specific signal for winters without major SSW.

\subsection{Inter-annual Evolution}

[28] The distribution of winter anomalies for the whole time series shows (Figure 5) different patterns depending on altitude. This reminds what was pointed out when looking at the winter anomalies evolution: the consequences of the occurrence of dynamical events vary with altitude.

[29] We now focus on the distribution of winter anomalies for each specific winter. Based on the mean distributions (Figure 5), we know that bimodal distributions can be expected. Using the methodology described in Appendix B, it is possible to identify the Gaussian, therefore to determine the abscissas of their peaks, which are called background contribution and dynamical contribution. Once again (see section 3.1), the SSWs almost always fall within the dynamical Gaussian.

[30] Trend estimates for these parameters are calculated using a linear fit of the parameters. The calculation of these trends is done over a three-decade period, from 1980 to 2009. Some years are excluded (depending on altitude) to avoid the perturbations caused by stratospheric aerosols, up to several months or even one or two years after the eruptions of El Chichon (April 82) and Pinatubo (June 91).

[31] At $40 \mathrm{~km}$ (Figure 6), the mean temperature decreases slightly over time $(-0.4 \pm 0.4 \mathrm{~K}$ per decade), as already calculated with standard multiregression analyses [Hauchecorne et al., 1991; Keckhut et al., 1995], while the background temperature's decrease is significantly greater $(-2 \pm 0.4 \mathrm{~K}$ per decade).

[32] Repeating these calculations at each altitude, it is now possible to compare the trend profiles of the background and the mean temperature for winter and summer periods

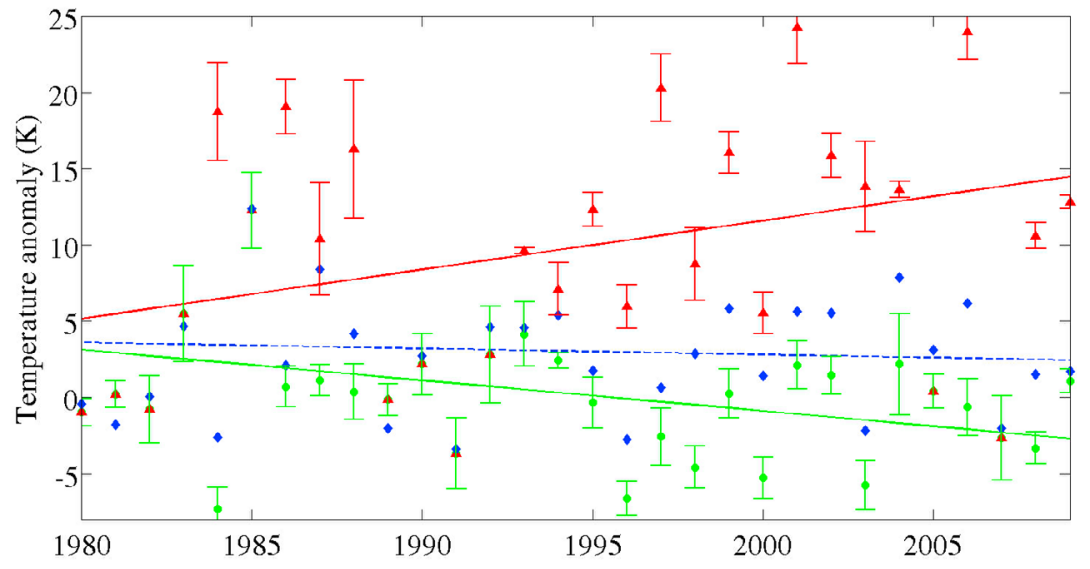

Figure 6. Linear winter trend estimates at $40 \mathrm{~km}$ : background contribution (green line and circles, dynamical contribution (red line and triangles) and mean anomaly (blue dashed line and diamonds). Dots represent the values calculated for each winter, and lines show the linear fits (some winters are excluded for trend calculation). Error bars are added for background and dynamical contributions. 


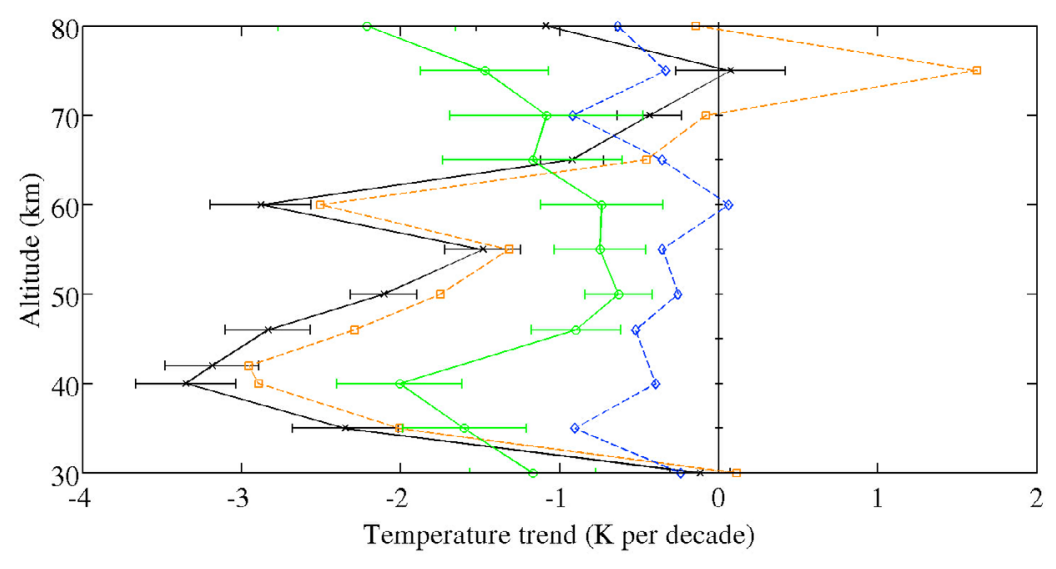

Figure 7. Compared linear trend profiles of the background temperature and the mean temperature for winter and summer periods. From left to right at $40 \mathrm{~km}$ : summer background trend (black line and crosses), summer mean trend (orange dashed line and squares), winter background trend (green line and circles) and winter mean trend (blue dashed line and diamonds). The total width of the error bars is 4 sigma.

(Figure 7). Winter and summer temperature trends based on monthly mean present a very different shape, notably around $40 \mathrm{~km}$. In summer, background and mean profiles are almost the same since there is no large dynamical contribution; therefore the most probable value is similar to the mean. In the high-mesosphere, summer trends look more positive than their winter counterparts, but the data quality at these altitudes is relatively low and, above all, the summer periods suffer from quite a bad sampling due to numerous factors (shorter nights, fewer days with good meteorological conditions, etc.), therefore the results concerning these high altitudes have to be considered with the utmost precaution. Concerning winter, the trend derived from the background temperature appears to be more negative than the mean trend at every altitude. Below $65 \mathrm{~km}$, the winter background profile is thus much closer to the summer estimates than the winter evolution given by mean values is. Overall, these observations are in good agreement with the well-documented cooling of the stratosphere [Ramaswamy et al., 2001; Eyring et al., 2006; Randel et al., 2009] and the mesosphere [Beig et al., 2003], and therefore tend to strengthen the validity of the hypothesis of temperature breakdown presented in section 3 . Our results can be compared to the vertical trend profiles found in previous studies based on observations or models: trends derived from Stratospheric Sounding Unit show a cooling of around $-1.4 \mathrm{~K}$ per decade at $3 \mathrm{hPa}$ [Shine et al., 2008], while Shine et al. [2003] report a "consensus" model-derived total trend of $-1.2 \mathrm{~K}$ per decade at $3 \mathrm{hPa}$. This is close to what our mean trends suggest, but the "background" trends show a larger cooling. The reinforced dynamical activity occurring in winter causes the apparent (mean) temperature trend to be less negative than the background one.

\section{Temperature Evolutions During Stratospheric Warmings}

\subsection{Methodology}

[33] In this section, the spatiotemporal representations focus on (major) SSWs. Although the aim is to identify the systematic features associated with SSWs, these events did not occur exactly at the same time in winter, as can be seen in Table 2 (the events' dates are provided, identified and classified using the method described by Charlton and Polvani [2007]). Therefore, composite evolutions are constructed by shifting the time axis to let the different SSWs be coincident.

[34] Concerning the localization, though the data used in this study is local, it is still both possible and meaningful to study the average of several events, as the location of the vortex relative to the earth's surface evolves roughly in the same way for SSWs of the same type [Matthewman et al., 2009].

\subsection{Results}

[35] Using the data from all of the 13 events listed, a composite of the winter temperature evolution during major SSWs can be calculated (Figure 8). To be able to associate it to SSWs, we can compare it to a reference like the seasonal winter evolution constructed previously with the data obtained during the 11 winters without major stratospheric warmings (Figure 4, top). The main structures are as follows:

[36] 1. Concerning the mesosphere, a warm and longlasting anomaly $(+6 \mathrm{~K}$ to $+12 \mathrm{~K})$ takes place at $80 \mathrm{~km}$ from 90 days up to 65 days before the event. It then descends to slightly lower levels $(70 \mathrm{~km})$ and lasts for the next month. These warm anomalies are not observed in the seasonal signal reported (Figure 4, top) and may be construed as a precursory signal of a major SSW.

[37] 2. Other anomalies, both warm $(+2 \mathrm{~K}$ to $+5 \mathrm{~K}$ at $55-$ $65 \mathrm{~km}$ around day -35$)$ and cold $(-4 \mathrm{~K}$ to $-8 \mathrm{~K}$ at 60 $65 \mathrm{~km}$ before day -40 , then at $65-75 \mathrm{~km}$ ) present some similarities to the reference seasonal evolution, though with rather smaller amplitude.

[38] 3. The high stratosphere $(30-50 \mathrm{~km})$ mostly displays warm anomalies $(+3 \mathrm{~K}$ to $+15 \mathrm{~K})$, especially the months before the SSW and up to a week after it.

[39] 4. After that date, a weaker warm anomaly (+1 K to $+4 \mathrm{~K}$ ) remains at level $30-40 \mathrm{~km}$ up to 80 days after the SSW. This warming is stronger and lasts longer than the one visible in the climatology (Figure 4, top), which means that after a major SSW, the stratosphere remains warmer. Note 


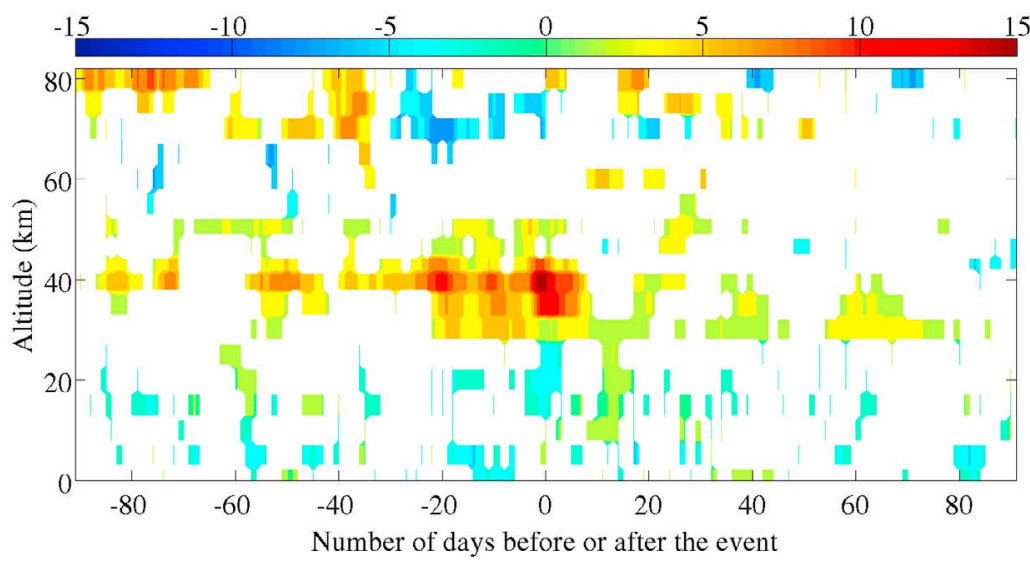

Figure 8. Composite SSW evolution (mean of 13 major SSWs from 1981 to 2009). The mean temperature anomaly is represented from 90 days before to 90 days after the date of the event.

that this composite evolution comprises two winters with two major SSWs, as one can see in Table 2. Nevertheless, there are not many consequences on the global features described above, as we verified by calculating the composite evolution without the concerned SSWs. Indeed, minor warmings often occur before the occurrence of major warmings, except in the early winter season.

[40] Similar temperature evolutions have been calculated considering only one of the two different types of (major) SSWs: split-type events (Figure 9) and displacement-type ones (Figure 10).

[41] The evolution of split-type SSWs is rather similar to the one of all SSWs (Figure 8) and presents the following structures.

[42] 1. A warm anomaly $(+3 \mathrm{~K}$ to $+10 \mathrm{~K})$ comparable to the one in Figure 8 can be seen in the upper mesosphere from day -90 to day -35 .

[43] 2. A similar though stronger warm anomaly (+2 K to $+8 \mathrm{~K})$ occurs in the upper stratosphere from day -80 to day -60. A maximum presenting the same intensity as the warming at the date of the $\mathrm{SSW}(+14 \mathrm{~K})$ is reached one month before the event.

[44] 3. As pointed out in the winter evolution for all SSWs, the warm anomaly then weakens $(+2 \mathrm{~K}$ to $+4 \mathrm{~K})$ and stays between $30 \mathrm{~km}$ and $40 \mathrm{~km}$ until day +80 .
[45] 4. The strongest cold anomaly $(-4 \mathrm{~K}$ to $-11 \mathrm{~K})$ occurs at altitudes from $60 \mathrm{~km}$ to $75 \mathrm{~km}$, simultaneously with the maximum warming of the stratosphere, in the same way as the one observed in Figure 8.

[46] 5. The troposphere features slightly more marked anomalies than for the picture of all SSWs, notably a cold anomaly in the lower troposphere which spreads around the date of the event and lasts 40 days; and a warm anomaly before and after this period, which starts with significant anomalies $(+4 \mathrm{~K}$ to $+6 \mathrm{~K})$ at the tropopause level ten days after the SSW. The more marked warm anomalies in the troposphere after split-type events may be connected with the fact that weak vortex signals propagate more easily downward to the troposphere for this type of SSWs [Nakagawa and Yamazaki, 2006].

[47] Concerning displacement-type events, they display some differences with other SSWs. Their main features are listed below.

[48] 1. The precursory warming occurring in the mesosphere is more intense $(+7 \mathrm{~K}$ to $+15 \mathrm{~K})$ and more limited in time (from day -85 to day -65 ) than the one visible for split-type events.

[49] 2. The main warming occurring in the upper stratosphere is composed of warm anomalies $(+8 \mathrm{~K}$ to $+14 \mathrm{~K})$ which arise regularly (every 18 days; see the vertical lines of

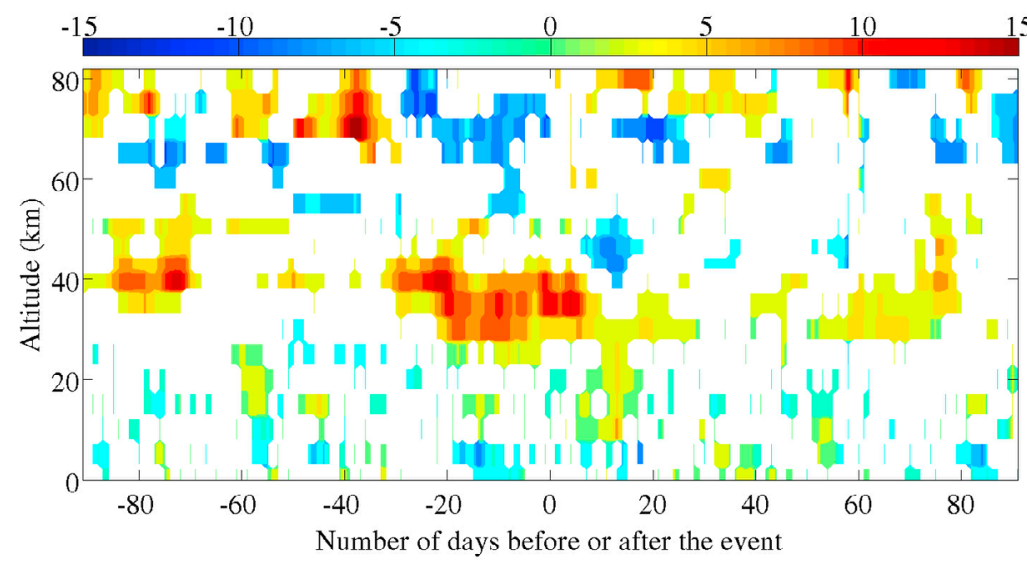

Figure 9. Composite split-type SSW evolution (mean of 7 events from 1985 to 2009). 


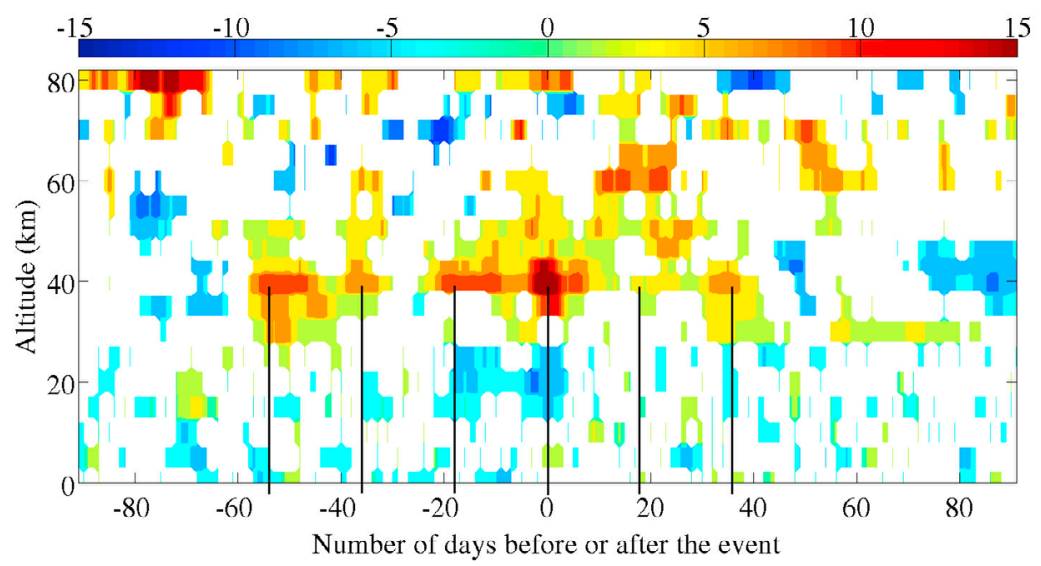

Figure 10. Composite displacement-type SSW evolution (mean of 6 events from 1981 to 2008). The vertical lines indicate the local maxima of anomalies around $40 \mathrm{~km}$. One of them corresponds to day 0 , and they are all separated by 18 days.

Figure 10) and are separated by short periods (3 to 5 days) with smaller anomalies $(-2 \mathrm{~K}$ to $+2 \mathrm{~K})$. This is in good agreement with the Rossby waves characteristics: the wave number one planetary wave, which shows the same periodicity, prevails for displacement-type events [Hauchecorne and Chanin, 1983]. However, the lifetime of such waves is usually close to a month: the observed periodicity seems to include various contributions, i.e., the occurrence of minor warmings, stratospheric vacillation, and amplification of quasi-stationary waves as well as 18-day waves [Hirota and Hirooka, 1984; Ahlquist, 1985].

[50] 3. Unlike split-type events, cold anomalies ( $-3 \mathrm{~K}$ to $-9 \mathrm{~K}$ ) take place in the upper stratosphere, and start as soon as 45 days after the event: from this day, the warming resulting from the SSW seems to be restricted to a thin layer centered on level $30 \mathrm{~km}$.

[51] 4. There is no large cooling at levels $60-70 \mathrm{~km}$ after the SSW (from day +10 to day +25 ), instead a warm anomaly appears $(+5 \mathrm{~K}$ to $+7 \mathrm{~K})$.

[52] 5. There is no significant change in the temperature anomaly of the troposphere, through all the winter. It stays between $-4 \mathrm{~K}$ to $+2 \mathrm{~K}$ with very slow evolutions.

\subsection{Comparison With Previous Investigations}

[53] Comparing our study with previous investigations is not easy since, to our knowledge, no similar statistical work regarding SSWs anomalies in the middle atmosphere has been performed with such comprehensive data series. Other studies are based on data sets either shorter (satellites), or of narrower vertical range, or displaying an insufficient time sampling (rockets). Nevertheless, for some aspects of our study, a few comparisons are possible.

[54] In regard to climatology, our results from local lidar measurements are corroborated by previous works considering either local or global data. We observe higher temperature variability in winter, which can be linked to Wilson et al.'s [1991] conclusion highlighting the maximum wave activity during this period. Moreover, a semi-annual component is found above $55 \mathrm{~km}$, which is close to the similar $60 \mathrm{~km}$ threshold described by Wilson et al. The anticorrelation between the mesosphere's temperatures and the upper stratosphere's has been emphasized by Hauchecorne and Chanin [1983], similarly to what we point out. Finally, a succession of warmings and coolings occurring at the same altitude and reaching high amplitudes in January was also mentioned by Hauchecorne and Chanin, which corroborates our findings. The background temperature profiles we found are in good agreement with the near global $\left(70^{\circ} \mathrm{S}-70^{\circ} \mathrm{N}\right)$ and annual mean trends (calculated over 1980 - 1999) reported in SPARC CCMVal [2010]: the different models show a cooling around $-0.8 \mathrm{~K}$ per decade at $10 \mathrm{hPa}$ while at $30 \mathrm{~km}$ our winter and summer components show a mean cooling of $-0.7 \pm 0.3 \mathrm{~K}$ per decade; the models indicate a cooling around $-1.6 \mathrm{~K}$ per decade between $1 \mathrm{hPa}$ and $2 \mathrm{hPa}$ while at $46 \mathrm{~km}$ we found $-1.9 \pm 0.3 \mathrm{~K}$ per decade.

[55] Now tackling the overall evolution of sudden stratospheric warmings, some of our conclusions are in good agreement with previous findings. Alternative regions of warming and cooling above the region of main warming were commented by Walterscheid et al. [2000]. They also highlighted the fact that regions of upper stratospheric warmings are associated with downward motion, which is visible in the different composite evolutions presented in this paper. This downward motion was also tackled by Whiteway and Carswell [1994]. A greater dissipation of gravity wave energy during the SSW (in comparison with preceding and following periods) was described, and can be linked to the strong warming we observe around $40 \mathrm{~km}$ for the same period. Baldwin and Dunkerton [2001] pointed out that large variations in the strength of the stratospheric circulation, appearing in the mesosphere, descend to the lowermost stratosphere and are followed by anomalous tropospheric weather regimes. This can be related to our findings as we witness noticeable temperature anomalies in the mesosphere reaching the stratosphere around the date of the SSW, a phenomenon which is the expression of substantial disturbances of the stratospheric circulation. We also notice anomalies in the troposphere correlated to the ones occurring at higher altitudes.

[56] On a global scale, a series of articles have addressed the issue of the statistical characterization of SSWs [Charlton and Polvani, 2007; Matthewman et al., 2009]. In these studies, the distinction between two types of SSWs was made (as also mentioned by Haynes [2005]), showing 
specific features for each case. As Matthewman et al. pointed out, the split-type events display a main warming occurring over a large altitude range. Besides, the middle stratospheric warming caused by split-type events lasts much longer (up to 30 days more) than for displacement-type events. In the present study, similar results are reported with the lidar series with even a longer duration (2 months). However, the slight difference we find between the two event's types at troposphere levels is not corroborated by Charlton and Polvani and could indicate a local effect. Hauchecorne and Chanin [1983] described an 18-days Rossby wave, suggesting its presence through all winter. Such an 18-days period signal is observed in our study before the appearance of the SSW, and proves to be stronger for displacement-type events, precisely like the SSW event analyzed by Hauchecorne and Chanin. Such oscillations have been established as well for the displacement-type SSW which occurred in 2004 [Pancheva et al., 2008], though displaying a slightly shorter period (16 days). These oscillations illustrate the vertical coupling of the stratosphere-mesosphere system through wave number one planetary waves. Indeed, planetary waves propagating up to the mesosphere may also help trigger stratospheric warmings [Coy et al., 2011; Sun et al., 2011]. The precursory warming we notice for displacement-type events in the high-mesosphere from one to three months before the SSW might be caused by gravity waves. These waves propagate vertically with energy deposition that can vary with altitude [Wilson et al., 1991], as suggested by the warm and cold anomalies we observe at the same time as the precursory warming and at lower altitudes. In conclusion, some of our findings corroborate previous studies but also specify which type of event (displacement or split) is more likely to be concerned.

\section{Discussion and Conclusions}

[57] Temperature trends measured at HPO by lidar have shown some differences in the upper stratosphere and in the lower mesosphere between winter and summer months. Analysis of the daily temperature anomalies suggests using the maxima noticed in the multimodal distributions instead of the mean, mainly during winter. One is clearly associated with SSWs, while the other has been identified as related to background conditions. The long-term trends of this latter maximum show during winter a larger cooling $(-2 \mathrm{~K}$ per decade) than when the mean temperature is used $(-0.4 \mathrm{~K}$ per decade). The cooling of the winter background temperature is then closer to the summer trend estimates, which are similar whichever the temperature proxy used (mean or background). The temperature anomalies associated with dynamical disturbances like SSWs show an increase in their intensity and occurrence that leads - when considering the mean trend - to partly cancel out the long-term background trend. This study does not allow to conclude on a global scale, but it shows that winter trends calculated with the monthly mean temperature include a large fraction of temperature anomalies which are not directly related to radiative processes and standard dynamical activity. The contribution of dynamics to trends may contribute to explain the differences observed between trend estimates derived from different data sets at different longitudes [Kubicki et al., 2006; Li et al., 2011; Keckhut et al., 2011]. It is also quite important to keep in mind when comparing measured temperature trends with numerical models, as the dynamical activity and mainly the occurrence of stratospheric warming are quite different from one model to another [Charlton et al., 2007; Austin et al., 2009; SPARC CCMVal, 2010]. The contribution of dynamics in the winter hemisphere may induce differences from one model to another.

[58] The temperature evolution during winter associated with SSWs has been calculated. There are several challenges to identify the temperature fluctuations related to a specific event like a SSW. The first one is the reference temperature. If it is the mean temperature, the results are biased by the SSWs themselves, because they induce large temperature disturbances as seen on the mean temperature and the sinusoidal annual evolution (Figure 3). The investigations on temperature distributions allow to identify a background temperature less sensitive to SSWs. Another difficulty lies in the fact that stratospheric warmings occur permanently during winter with different intensities. Therefore, the investigation focuses on major events because they lead to an irreversible breakdown of the vortex associated with a wind reversal which is easy to identify. The third difficulty relates to the dates of major SSWs: they occur preferentially in January but the exact date may vary from a year to another. Because this event is due to a nonlinear interaction between planetary waves and the mean flow, a certain degree of randomness in the time of occurrence needs to be taken into account. Whereas qualitatively the occurring of a SSW is related to the planetary waves' activity and to the mean flow, the exact conditions required to generate such an event are not fully known. To better identify the signal associated with SSWs, a composite time evolution has been displayed using all the data before and after each major SSW, with the time axis shifted according to the date of the event. Other similar time evolutions were also plotted considering only split-type SSWs or displacement-type SSWs.

[59] In all cases the maximum warming is observed at the time of the SSW around the altitudes from $40 \mathrm{~km}$ to $50 \mathrm{~km}$, with mean amplitudes of more than $10 \mathrm{~K}$. Warm temperatures at this height are noticed two months before the date of the SSW and up to a week after. This confirms that major SSWs lead to an overall warm winter (in the stratosphere) with a possible low occurrence of polar stratospheric clouds. However, during displacement SSWs some short cold periods can occur, leading to sporadic polar stratospheric clouds over Europe [Keckhut et al., 2007]. Indeed, the warming is rather continuous for split-type events, whereas for displacement-type SSWs it features an obvious periodicity close to the one characteristic of the Rossby wave. It has already been recognized that the wave number one of the Rossby wave was associated with displacement SSWs, while a predominance of waves with larger wave numbers is required to obtain split-type events.

[60] Composite time evolutions seem to show a possible harbinger in the upper mesosphere, suggesting the role of gravity waves. While the mean seasonal temperature evolution also exhibits a precursory signal in the mesosphere, it appears to be stronger for the winters including a major SSW; and the signal observed for the seasonal evolution is probably a contribution of all the minor warmings occurring several times each winter. One month before the SSW happens, the warm anomaly pointed out in the mesosphere propagates rapidly to the stratosphere (in about one week). 
Table A1. Sets of Initial Guesses Used for the Two-Gaussians Fit Function

\begin{tabular}{cccccc}
\hline & \multicolumn{2}{c}{ First Gaussian } & & \multicolumn{2}{c}{ Second Gaussian } \\
\cline { 2 - 3 } $\begin{array}{c}\text { Number of the } \\
\text { Set of Guesses }\end{array}$ & Mean & $\begin{array}{c}\text { Standard } \\
\text { Deviation }\end{array}$ & & Mean & $\begin{array}{c}\text { Standard } \\
\text { Deviation }\end{array}$ \\
\cline { 2 - 3 } 1 & $\mathrm{~T}-\sigma$ & $\sigma$ & $\mathrm{T}$ & $\sigma / 2$ \\
2 & $\mathrm{~T}-\sigma$ & $\sigma / 2$ & & $\mathrm{~T}$ & $\sigma$ \\
3 & $\mathrm{~T}-\sigma$ & $\sigma$ & & $\mathrm{T}+\sigma$ & $\sigma / 2$ \\
4 & $\mathrm{~T}-\sigma$ & $\sigma / 2$ & & $\mathrm{~T}+\sigma$ & $\sigma$ \\
5 & $\mathrm{~T}$ & $\sigma$ & & $\mathrm{T}+\sigma$ & $\sigma / 2$ \\
6 & $\mathrm{~T}$ & $\sigma / 2$ & & $\mathrm{~T}+\sigma$ & $\sigma$ \\
\hline
\end{tabular}

[61] Finally, a warm anomaly propagating down to ground level can be seen from 10 days after the SSW to 60 days after. This effect is even more pronounced for split-type events. This is in good agreement with the propagation of the North Atlantic Oscillation reported by Baldwin and Dunkerton [2001].

\section{Appendix A: Extraction of the Background Temperature}

[62] We consider, at each level, the distribution of the temperature anomalies (measured temperatures to which we subtract a 15-days running average annual cycle) during one of the 24 fifteen-days period of the year (first half of January, second half of January, first half of February etc.), using all the data available (i.e., around 30 years, depending on the period studied). Figure 2 shows two examples. This distribution is fitted by a function which represents the sum of two Gaussians. Initial guesses concerning the mean and the standard deviation of each Gaussian have to be provided to run the fitting program. The program is run 6 times with different initial guesses. Here is how these 6 set of guesses are determined. First, we run a simple Gaussian fit (for the same distribution) which gives a mean value $\mathrm{T}$ and a standard deviation $\sigma$. The 6 set of guesses are the 6 different possible combinations when using the abscissas $\mathrm{T}-\sigma, \mathrm{T}$ and $\mathrm{T}+\sigma$, and setting the standard deviations to $\sigma$ and $\sigma / 2$ for the two Gaussians. These guesses are listed in Table A1. Quite often the resulting two-Gaussians fit is the same in all 6 cases. If not, the case we select is determined using the method of least squares (we choose the case which minimizes the sum of squared residuals). Then, the bigger Gaussian is identified as the background one. In summer periods or at low altitudes (below $20 \mathrm{~km}$ ), the integral of the bigger Gaussian is almost always at least 20 times greater than the one of the smaller Gaussian, in which case the distribution is considered as monomodal, and then a one-Gaussian fit is done (resulting in almost the exact same mean and standard deviation values as the ones of the bigger Gaussian of the former two-Gaussians fit).

\section{Appendix B: Determination of Winter Parameters}

[63] We consider, at each level, the distribution of wintertime (ONDJFM) temperatures anomalies (measured temperatures to which we subtract the sinusoidal background temperature annual cycle from equations (2) and (3)) for one winter. We apply the same protocol as the one described in appendix A to determine a double-Gaussian fit. We then calculate the distance between the two Gaussians (the absolute value of the difference between their abscissas): if it is greater than the smaller of the two standard deviations, the two Gaussians are considered as being separated enough to be distinguished, and the Gaussian with the mean abscissa closer to 0 is identified as the background one. Else, we apply a criterion, depending on the altitude, to identify the Gaussians either by their positions (abscissas of their peaks) or their sizes (integrals). This criterion is determined with the study of the distribution of temperature anomalies (measured temperatures to which we subtract the background annual cycle) for all (30) winters (Figure 5 shows three examples). This distribution is fitted by a two-Gaussian function, once again with the same protocol used. The bigger Gaussian is identified as the background one, the other is the dynamical one. The criterion is the parameter (either the position or the size) which allows to better distinguish between the two Gaussians. Here is how it is determined. We compare two ratios: the position ratio (the distance between the two Gaussians divided by the smallest standard deviation) and the size ratio (the integral of the bigger Gaussian divided by the integral of the smaller one). The greatest of the two ratios dictates the criterion used. If it is the size, the bigger of the two Gaussians in the one-winter distribution is identified as the background one. If it is the position, we look at the distribution for all winters to determine the position of the bigger (background) Gaussian relative to the position of the smaller (dynamical) one; then we can identify the Gaussians of the one-winter distribution.

[64] Acknowledgments. This work has been made in the frame of the FP7 EU project ARISE (Atmospheric dynamics InfraStructure in Europe) 284387 and the LEFE-CHAT national project IDSC (Influence Dynamique de la Stratosphere sur le Climat). Lidar measurements at Haute-Provence Observatory were obtained in the frame of the NDACC (Network for the Detection of Atmospheric Composition Changes) with the support of INSU (Institut des Sciences de l'Univers), CNES (Centre National d'Etudes Spatiales), UVSQ (Université de Versailles Saint-Quentin-en-Yvelines) and ESA-VALID (VAlidation with LIDar) project. Data are available publicly through the NDACC-NOAA (http://www.ndsc.ncep.noaa.gov) or ETHER (http://ether.ipsl.jussieu.fr/NDACC) databases. The authors want to thank Andrew Charlton for providing updated dates of Sudden Stratospheric Warmings.

Ahlquist, J. E. (1985), Climatology of normal mode Rossby waves, J. Atmos. Sci., 42, 2059-2068, doi:10.1175/1520-0469(1985)042<2059: CONMRW $>2.0 . \mathrm{CO} ; 2$.

Andrews, D. G., J. R. Holton, and C. B. Leovy (1987), Middle Atmosphere Dynamics, Academic, San Diego, Calif.

Austin, J., et al. (2009), Coupled chemistry climate model simulations of stratospheric temperatures and their trends for the recent past, Geophys. Res. Lett., 36, L13809, doi:10.1029/2009GL038462.

Baldwin, M. P., and T. J. Dunkerton (2001), Stratospheric harbingers of anomalous weather regimes, Science, 294, 581-584, doi:10.1126/ science. 1063315 .

Beig, G., et al. (2003), Review of mesospheric temperature trends, Rev. Geophys., 41(4), 1015, doi:10.1029/2002RG000121.

Cagnazzo, C., C. Claud, and S. Hare (2006), Aspects of stratospheric longterm changes induced by ozone depletion, Clim. Dyn., 27, 101-111, doi:10.1007/s00382-006-0120-1.

Charlton, A. J., and L. M. Polvani (2007), A new look at stratospheric sudden warmings. Part I: Climatology and modeling benchmarks, J. Clim., 20(3), 449-469, doi:10.1175/JCLI3996.1.

Charlton, A. J., L. M. Polvani, J. Perlwitz, F. Sassi, E. Manzini, K. Shibata, S. Pawson, J. E. Nielsen, and D. Rind (2007), A new look at stratospheric sudden warmings. Part II: Evaluation of numerical model simulations, J. Clim., 20(3), 470-488, doi:10.1175/JCLI3994.1.

Cho, Y.-M., G. G. Shepherd, Y.-I. Won, S. Sargoytchev, S. Brown, and B. Solheim (2004), MLT cooling during stratospheric warming events, Geophys. Res. Lett., 31, L10104, doi:10.1029/2004GL019552. 
Coy, L., S. D. Eckermann, K. W. Hoppel, and F. Sassi (2011), Mesospheric precursors to the major stratospheric sudden warming of 2009: Validation and dynamical attribution using a ground-to-edge-of-space data assimilation system, J. Adv. Model. Earth Syst., 3, M10002, doi:10.1029/ 2011MS000067.

David, C., P. Keckhut, A. Armetta, J. Jumelet, M. Marchand, and S. Bekki (2009), Radiosondes stratospheric temperatures from 1957 to 2008 in Dumont d'Urville (Antarctica): Trends and link with polar stratospheric clouds, Atmos. Chem. Phys. Discuss., 9, 25,687-25,722, doi:10.5194/ acpd-9-25687-2009.

Dunkerton, T. J., D. P. Delisi, and M. P. Baldwin (1998), Middle atmosphere cooling trend in historical rocketsonde data, Geophys. Res. Lett. 25, 3371-3374, doi:10.1029/98GL02385.

Eyring, V., et al. (2006), Assessment of temperature, trace species, and ozone in chemistry-climate model simulations of the recent past, J. Geophys. Res., 111, D22308, doi:10.1029/2006JD007327.

Flury, T., K. Hocke, N. Kämpfer, and D. L. Wu (2010), Enhancements of gravity wave amplitudes at midlatitudes during sudden stratospheric warmings in 2008, Atmos. Chem. Phys. Discuss., 10, 29,971-29,995, doi:10.5194/acpd-10-29971-2010.

Funatsu, B. M., C. Claud, P. Keckhut, and A. Hauchecorne (2008), Crossvalidation of AMSU and lidar for long-term upper stratospheric temperature monitoring, J. Geophys. Res., 113, D23108, doi:10.1029/2008JD010743.

Funatsu, B. M., C. Claud, P. Keckhut, W. Steinbrecht, and A. Hauchecorne (2011), Investigations of stratospheric temperature regional variability with lidar and AMSU, J. Geophys. Res., 116, D08106, doi:10.1029/ 2010JD014974.

Godin, S., M. Marchand, A. Hauchecorne, and F. Lefèvre (2002), Influence of Arctic polar ozone depletion on lower stratospheric ozone amounts at Haute-Provence Observatory $\left(43.92^{\circ} \mathrm{N}, 5.71^{\circ} \mathrm{E}\right), J$. Geophys. Res., 107(D20), 8272, doi:10.1029/2001JD000516.

Hare, S. H. E., L. J. Gray, W. A. Lahoz, A. O’Neill, and L. Steenman-Clark (2004), Can stratospheric temperature trends be attributed to ozone depletion?, J. Geophys. Res., 109, D05111, doi:10.1029/2003JD003897.

Hauchecorne, A., and M. Chanin (1980), Density and temperature profiles obtained by lidar between 35 and $70 \mathrm{~km}$, Geophys. Res. Lett., 7(8), 565-568, doi:10.1029/GL007i008p00565.

Hauchecorne, A., and M. L. Chanin (1983), Mid-latitude lidar observations of planetary waves in the middle atmosphere during the winter of 1981-1982, J. Geophys. Res., 88(C6), 3843-3849, doi:10.1029/JC088iC06p03843.

Hauchecorne, A., and M. L. Chanin (1988), Planetary waves-mean flow interaction in the middle atmosphere: Modelisation and comparison with lidar observations, Ann. Geophys., 6, 409-416.

Hauchecorne A., M. L. Chanin, and P. Keckhut (1991), Climatology and trends of the middle atmospheric temperature $(33-87 \mathrm{~km})$ as seen by Rayleigh lidar over the south of France, J. Geophys. Res., 96, 15,297-15,309.

Haynes, P. H. (2005), Stratospheric dynamics, Annu. Rev. Fluid Mech., 37, 263-293, doi:10.1146/annurev.fluid.37.061903.175710.

Hirota, I., and T. Hirooka (1984), Normal mode Rossby waves observed in the upper stratosphere. Part I: First symmetric modes of zonal wavenumbers 1 and 2, J. Atmos. Sci., 41, 1253-1267, doi:10.1175/1520-0469 (1984) $041<1253$ :NMRWOI $>2.0 . \mathrm{CO} ; 2$.

Hoffmann, P., W. Singer, D. Keuer, W. K. Hocking, M. Kunze, and Y. Murayama (2007), Latitudinal and longitudinal variability of mesospheric winds and temperatures during stratospheric warming events, J. Atmos. Sol. Terr. Phys., 69, 2355-2366, doi:10.1016/j.jastp.2007.06.010.

Jeannet, P., C. Bower, and B. Calpini (2008), Global criteria for tracing the improvements of radiosondes over the last decades, Instrum. Obs. Methods Rep. 95, 32 pp., WMO, Geneva, Switzerland. [Available at http://www. wmo.int/pages/prog/gcos/documents/gruanmanuals/CIMO IOM/Tracingimprov_last-decades.pdf.]

Keckhut, P., A. Hauchecorne, and M. L. Chanin (1993), A critical review on the data base acquired for the long-term surveillance of the middle atmosphere by French Rayleigh lidars, J. Atmos. Oceanic Technol., 10, 850-867, doi:10.1175/1520-0426(1993)010<0850:ACROTD>2.0.CO;2.

Keckhut, P., A. Hauchecorne, and M. L. Chanin (1995), Midlatitude longterm variability of the middle atmosphere trends, and cyclic and episodic changes, J. Geophys. Res., 100, 18,887-18,897, doi:10.1029/95JD01387.

Keckhut, P., et al. (2004), Review of ozone and temperature lidar validations performed within the framework of the network for the detection of stratospheric change, J. Environ. Monit., 6, 721-733, doi:10.1039/ b404256e.

Keckhut, P., C. Cagnazzo, M.-L. Chanin, C. Claud, and A. Hauchecorne (2005), The 11-year solar-cycle in the temperature in the upper stratosphere and mesosphere: Part I. Assessment of observations, J. Atmos. Sol. Terr. Phys., 67, 940-947, doi:10.1016/j.jastp.2005.01.008.

Keckhut, P., C. David, M. Marchand, S. Bekki, J. Jumelet, A. Hauchecorne and M. Höpfner (2007), Observation of a polar stratospheric cloud down to the Mediterranean coast, Atmos. Chem. Phys., 7, 5275-5281, doi:10.5194 acp-7-5275-2007.

Keckhut, P., et al. (2011), An evaluation of uncertainties in monitoring middle atmosphere temperatures with the ground-based lidar network in support of space observations, J. Atmos. Sol. Terr. Phys., 73(5-6), 627-642, doi:10.1016/j.jastp.2011.01.003.

Kerzenmacher, T. E., P. Keckhut, A. Hauchecorne, and M. L. Chanin (2006), Methodological uncertainties in multi-regression analyzes of middle-atmospheric data series, J. Environ. Monit., 8, 682-690, doi:10.1039/ b603750j.

Kubicki, A., P. Keckhut, M.-L. Chanin, A. Hauchecorne, E. Lysenko, and G.-S. Golitsyn (2006), Temperature trends in the middle atmosphere of the mid-latitude as seen by historical Russian rocket launches: Part 1 Volgograd $\left(48,68^{\circ} \mathrm{N}, 44,35^{\circ} \mathrm{E}\right)$, J. Atmos. Sol. Terr. Phys., 68, 1075-1086, doi:10.1016/j.jastp.2006.02.001.

Labitzke, K. (1972), Temperature changes in the mesosphere and stratosphere connected with circulation changes in winter, J. Atmos. Sci., 29(4), 756-766, doi:10.1175/1520-0469(1972)029<0756:TCITMA > 2.0.CO;2.

Labitzke, K. (1981), Stratospheric-mesospheric midwinter disturbances: A summary of observed characteristics, J. Geophys. Res., 86(C10), 9665-9678, doi:10.1029/JC086iC10p09665.

Leblanc, T., I. S. McDermid, P. Keckhut, A. Hauchecorne, C. Y. She, and D. A. Krueger (1998), Temperature climatology of the middle atmosphere from long-term lidar measurements at middle and low latitudes, J. Geophys. Res., 103, 17,191-17,204, doi:10.1029/98JD01347.

Li, T., T. Leblanc, I. S. McDermid, P. Keckhut, A. Hauchecorne, and $X$. Dou (2011), Middle atmosphere temperature trend and solar cycle revealed by long-term Rayleigh lidar observations, J. Geophys. Res. 116, D00P05, doi:10.1029/2010JD015275.

Liu, H. L., and R. G. Roble (2002), A study of a self-generated stratospheric sudden warming and its mesospheric-lower thermospheric impacts using the coupled TIME-GCM/CCM3, J. Geophys. Res., 107(D23), 4695, doi:10.1029/2001JD001533.

Matsuno, T. (1971), A dynamical model of the stratospheric sudden warming, J. Atmos. Sci., 28, 1479-1494, doi:10.1175/1520-0469(1971)028<1479: ADMOTS $>2.0 . \mathrm{CO} ; 2$

Matthewman, N. J., J. G. Esler, A. J. Charlton-Perez, and L. M. Polvani (2009), A new look at stratospheric sudden warmings. Part III: Polar vortex evolution and vertical structure, J. Clim., 22, 1566-1585, doi:http://dx.doi.org/10.1175/2008JCLI2365.1.

Nakagawa, K. I., and K. Yamazaki (2006), What kind of stratospheric sudden warming propagates to the troposphere?, Geophys. Res. Lett., 33, L04801, doi:10.1029/2005GL024784.

Nishizawa, S., and S. Yoden (2005), Distribution functions of a spurious trend in a finite length data set with natural variability: Statistical considerations and a numerical experiment with a global circulation model, J. Geophys. Res. 110, D12105, doi:10.1029/2004JD005714.

O'Neill, A. (2003), Middle atmosphere: Stratospheric sudden warmings, in Encyclopedia of Atmospheric Sciences, edited by J. R. Holton, J. A. Curry, and J. A. Pyle, pp. 1342-1353, Academic, San Diego, Calif., doi:10.1016/B0-12-227090-8/00230-X.

Pancheva, D., et al. (2008), Planetary waves in coupling the stratosphere and mesosphere during the major stratospheric warming in 2003/2004, J. Geophys. Res., 113, D12105, doi:10.1029/2007JD009011.

Ramaswamy, V., et al. (2001), Stratospheric temperature trends: Observations and model simulations, Rev. Geophys., 39(1), 71-122, doi:10.1029/ 1999RG000065.

Randel, W. J., et al. (2009), An update of observed stratospheric temperature trends, J. Geophys. Res., 114, D02107, doi:10.1029/2008JD010421. Rind, D., D. Shindell, P. Lonergan, and N. K. Balachandran (1998), Climate change and the middle atmosphere. Part III: The doubled $\mathrm{CO}_{2}$ climate revisited, J. Clim., 11, 876-894, doi:10.1175/1520-0442(1998) $011<0876$ :CCATMA>2.0.CO;2.

She, C. Y., J. R. Yu, D. A. Krueger, R. Roble, P. Keckhut, A. Hauchecorne, and M. L. Chanin (1995), Vertical structure of midlatitude temperature from stratosphere to mesopause (30-105 km), Geophys. Res. Lett., 22, 377-380, doi:10.1029/95GL00010.

Shine, K. P., et al. (2003), A comparison of model-simulated trends in stratospheric temperatures, Q. J. R. Meteorol. Soc., 129, 1565-1588, doi:10.1256/qj.02.186.

Shine, K. P., J. J. Barnett, and W. J. Randel (2008), Temperature trends derived from Stratospheric Sounding Unit radiances: The effect of increasing $\mathrm{CO}_{2}$ on the weighting function, Geophys. Res. Lett., 35 , L02710, doi:10.1029/2007GL032218.

Singh, U. N., P. Keckhut, T. J. McGee, M. R. Gross, A. Hauchecorne, E. F Fishbein, J. W. Waters, J. C. Gille, A. E. Roche, and J. M. Russell III (1996), Stratospheric temperature measurements by two collocated NDSC lidars during UARS validation campaign, J. Geophys. Res., 101(D6), 10,287-10,297, doi:10.1029/96JD00516. 
SPARC CCMVal (2010), SPARC report on the evaluation of chemistryclimate models, SPARC Rep. 5, WMO, Geneva, Switzerland. [Available at http://www.sparc-climate.org/publications/sparc-reports/sparc-report-no5/.]

Sun, L., W. A. Robinson, and G. Chen (2011), The predictability of stratospheric warming events: More from the troposphere or the stratosphere?, J. Atmos. Sci., 69, 768-783, doi:10.1175/JAS-D-11-0144.1.

Thompson, W. J., and J. M. Wallace (1998), The Arctic Oscillation signature in the wintertime geopotential height and temperature fields, Geophys. Res. Lett., 25, 1297-1300, doi:10.1029/98GL00950.

von Zahn, U., G. von Cossart, J. Fiedler, and D. Rees (1998), Tidal variations of noctilucent clouds measured at $69^{\circ} \mathrm{N}$ latitude by groundbased lidar, Geophys. Res. Lett., 25, 1289-1292, doi:10.1029/98GL00546.

Walterscheid, R. L., G. G. Sivjee, and R. G. Roble (2000), Mesospheric and lower thermospheric manifestations of a stratospheric warming event over Eureka, Canada $\left(80^{\circ} \mathrm{N}\right)$, Geophys. Res. Lett., 27(18), 2897-2900, doi:10.1029/2000GL003768.
Weatherhead, E. C., et al. (1998), Factors affecting the detection of trends: Statistical considerations and applications to environmental data, J. Geophys. Res., 103(D14), 17,149-17,161, doi:10.1029/98JD00995.

Whiteway, J. A., and A. I. Carswell (1994), Rayleigh lidar observations of thermal structure and gravity wave activity in the high arctic during a stratospheric warming, J. Atmos. Sci., 51, 3122-3136, doi:10.1175/ 1520-0469(1994)051<3122:RLOOTS $>2.0 . \mathrm{CO} ; 2$.

Wild, J. D., et al. (1995), Comparison of stratospheric temperatures from several lidars, using National Meteorological Center and microwave limb sounder data as transfer references, J. Geophys. Res., 100(D6), 11,105-11,111, doi:10.1029/95JD00631.

Wilson, R., M. L. Chanin, and A. Hauchecorne (1991), Gravity waves in the middle atmosphere observed by Rayleigh lidar: 2. Climatology, J. Geophys. Res., 96, 5169-5183, doi:10.1029/90JD02610. 